\title{
Simulation of Combustion Process of Diesel and Ethanol Fuel in Reactivity Controlled Compression Ignition Engine
}

\author{
Fatin Farhanah Zulkurnai ${ }^{1}$, Wan Mohd Faizal Wan Mahmood ${ }^{1}$, Norhidayah Mat Taib ${ }^{1}$, Mohd Radzi \\ Abu Mansor ${ }^{1, *}$
}

Department of Mechanical and Manufacturing Engineering, Faculty of Engineering and Built Environment, Universiti Kebangsaan Malaysia, 43600 UKM Bangi, Selangor, Malaysia

\section{ARTICLE INFO ABSTRACT}

\section{Article history:}

Received 24 December 2020

Received in revised form 15 February 2021

Accepted 23 February 2021

Available online 27 February 2021

\section{Keywords:}

Combustion characteristics; emissions; engine speed; injection timing; fuel reactivity

\begin{abstract}
Reactivity controlled compression ignition $(\mathrm{RCCl})$ engine give advantages over conventional diesel engine with the promising engine power and good control on NOx and soot emission. The trend of the RCCl concept is still new and Is very important to control the ignition in order to control the combustion progress and emission. The objective of this study is to provide data on the combustion characteristics and emission of diesel as high reactive, and ethanol as the low reactive fuel in the RCCl engine. The engine speed and injection timing were varied. Simulation work was conducted by using the Converge CFD software based on the Yanmar TF90 diesel engine parameter. Results show that operating the engine at low speed resulting in better engine performance and low carbon emissions due to the sufficient oxygen contents. For the high-speed engine, advancing the injection timing improves the fuel and air reactivity and steeper the equivalence ratio gradient, which result in a complete combustion process.
\end{abstract}

\section{Introduction}

Biofuels have been often proposed as an alternative fuel for internal combustion engines. Utilizing biofuels and producing them by the suitable method can reduce the operational cost, reduce petroleum dependency and decrease the emission considerably [1]. Many studies have examined the impact of blending various oxygenated additives with diesel or biodiesel fuels on engine performance and emission characteristics of diesel engines. Alcohol fuel such as ethanol is difficult to mix with diesel fuel at standard air temperature as these fuels exhibit tendencies for phase separation due to their physical properties differences [2].

However, ethanol seems to be the most eco-friendly solution as it is naturally produced from natural sources. Ethanol can be abundantly produced from any plant which contains sugar or other

\footnotetext{
* Corresponding author.

E-mail address: radzi@ukm.edu.my (Mohd Radzi Abu Mansor)
} 
components that can be converted into sugar, such as starch or cellulose, through the fermentation, distillation, and dehydration processes [3]. Due to that reason, the production cost of ethanol is relatively low and is considered the most economical for engine fuel. Initially, ethanol was associated with spark-ignition engines as it can be easily blended with gasoline. More recently, ethanol has been used as a fuel for diesel engines due to the advantages of the high power of diesel engines. However, ethanol has a high heat of evaporation $(840 \mathrm{~kJ} / \mathrm{kg})$, can be characterized by a very low cetane number ( 11), and high auto-ignition temperature (693K) [4].

Ethanol is not suggested to be mixed before the injection or directly used in diesel engines without any assist due to its properties. Ethanol fuel is generally used by using dual-fuel technology or blending with conventional diesel fuel with the presence of additives. Prashant et al., [5] has investigated the potential of diesel-ethanol blend in a 4-cylinder-turbocharger $62.5 \mathrm{~kW}$ gen-set dualfuel diesel engine. It was found that at low load conditions, $40 \%$ ethanol fraction lengthen the ignition delay. However, at higher load, ignition delay was found to be shortened. The peak of in-cylinder pressure was increasing in all the cases.

Huang et al., [6] investigated the application of blends of ethanol and diesel in a diesel engine. The test results discovered that it is reasonable and relevant for the blends to replace pure diesel as the fuel for the diesel engine. The thermal efficiency of the engine fueled by the blends was comparable to the pure-diesel fuel. However, the lower heating value of ethanol results in high fuel consumption. From the emission characteristics analysis, carbon monoxide (CO) was found to be reduced when the engine ran at and above its half loads. Meanwhile, CO emissions were found to increase at low loads and low speeds. Besides, the hydrocarbon $(\mathrm{HC})$ emissions from the blends combustion were all high except for the top loads at high speed and the nitrogen oxides $\left(\mathrm{NO}_{\mathrm{x}}\right)$ emissions show different trends for different engine speeds, loads, and percentage of ethanol [6].

The conventional diesel engine offers high engine efficiency. However, reactivity controlled compression ignition ( $\mathrm{RCCl}$ ) is better for the wide range operation with its capabilities to operate in a wide range of loads and achieve near-zero NOx and soot emissions. The RCCl engine can provide the combustion phasing by using two different reactivity fuels. In an $\mathrm{RCCl}$ engine, the ignition timing also can be controlled by adjusting the start of injection (SOI) timing with the ratio of diesel and other fuel [7]. Hansen et al., [8] explored the dual injection of diesel operating on different load and engine speed range. The experiment also proposed the single fuel injection strategies by premix the high reactive and low reactive fuel before injected known as premixed charged compression ignition (PCCI). Diesel fuel is injected at $-62^{\circ} \mathrm{CA}$ ATDC and injected again at $-37^{\circ} \mathrm{CA}$ ATDC. The higher engine speeds and lower intake temperature retarded the combustion phasing and results in poor in mixture stratification and decrease the pressure release rate (PRR).

In another research, a comparison between early and late injection strategies of high reactivity fuel (i.e., diesel) was experimentally performed on a gasoline/diesel $\mathrm{RCCl}$ engine by $\mathrm{Ma}$ et al., [9]. When the diesel fuel is injected earlier, the reactivity of the mixture plays a significant role in maintaining the reaction activity and concentration stratification to improve the thermal efficiency [10]. However, when the diesel fuel is injected later, the mixture stratification plays a considerable role. The study shows that the control of SOI can reduce the $\mathrm{HC}$ and $\mathrm{CO}$ emissions while increasing the combustion efficiency. However, the reduction of injection pressure and pressure rate (PR) while advancing the injection timing can also increase the $\mathrm{HC}$ and $\mathrm{CO}$ emissions [11].

This study focuses on the effect of high reactive fuel (HRF) and low reactive fuel (LRF) in the RCCI engine on engine efficiency, combustion characteristics, and emissions. Injection strategies are carried out to investigate the suitable injection timing of diesel to overcome the problem of combustion efficiency deficit and control the emission of $\mathrm{HC}$ and $\mathrm{CO}$. The engine parameters in this study were based on Ibrahim et al., [12] by using the numerical method from a CONVERGE CFD 
software. Other than experimental tests, numerical simulation studies can provide faster and accurate results without the need to modify the engine design. Hence, the data provided in this research will contribute to the information and propose as a suitable parameter for the future experimental work of diesel and ethanol in the $\mathrm{RCCl}$ engine.

\section{Methodology}

In this study, the simulation work approach were used and validated by performing the grid independence test. Combustion characteristics and emission of combustion were analyzed with respect to the different engine parameters.

\subsection{Validation Model}

Yanmar TF90 engine combustion chamber was modeled using Converge CFD software [13]. Converge CFD is specially equipped with an adaptive mesh refinery (AMR) function to automatically generate a perfectly orthogonal, structured grid at runtime based on simple, user-defined grid control parameters. Hence, there is no longer manual grid generation needed. Simulations were conducted based on the combustion chamber parameters from a single-cylinder Yanmar TF90 diesel engine. This engine is a horizontal, 4 cycles, water-cooled diesel engine and it is commonly used for agricultural purposes. The combustion chamber model of the engine is shown in Figure 1.

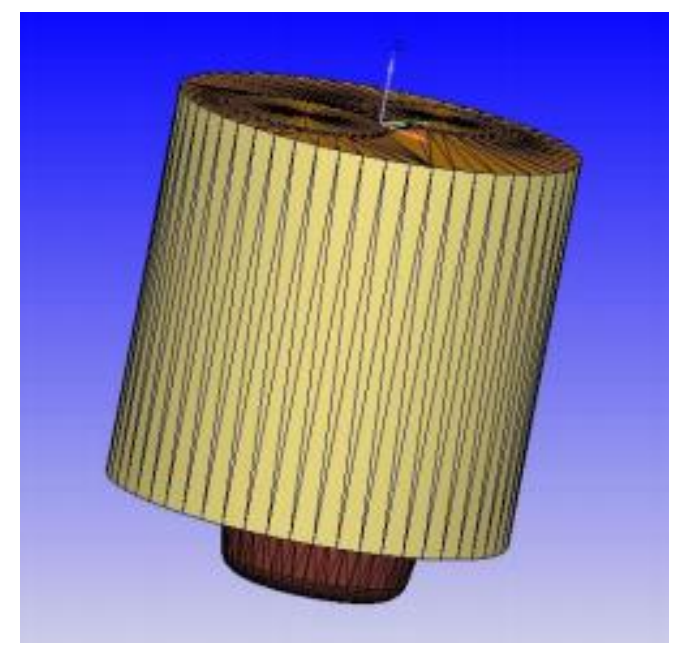

Fig. 1. CFD model combustion chamber based on Yanmar TF90 Engine parameter

The geometry consists of a grid with a base size of $4 \mathrm{~mm}$. To speed up the calculations, AMR grid control features and fixed embedding are used in this software. AMR group consists of velocity and temperature. Upon the injection of diesel fuel, the fixed embedding is activated and set for all the boundaries in the geometry. The simulation operates from the intake valve close (IVC) until the exhaust valve open (EVO). Wall temperatures for piston, cylinder head, and liner are set up according to research from Ibrahim, 2017 [12].

In this simulation, the port fuel injected low reactivity fuel (LRF) which is ethanol is considered homogeneously mixed and vaporized with intake air at IVC. Meanwhile, diesel fuel is directly injected as the high reactivity fuel (HRF) into the combustion chamber. KH-RT model is used for spray atomization and break up model. In spray modeling, the O'Rourke model is set for turbulent dispersion and the NTC collision model is used for collision model for a faster collision calculation. 
The 3D model was validated by comparing the results of diesel combustion from simulation and the experimental work obtained from Ibrahim, 2017 [12]. Table 1 shows the specification of the engine and the injection parameters set up in the simulation. The piston of the engine is equipped with the bowl to enhance the airflow movement for better mixing of fuel and air. The injection system in this engine is equipped with 2 injectors, one for port injection for low reactive fuel (ethanol) and one for in-cylinder direct injection for high reactive fuel (diesel).

The results of in-cylinder pressure and heat release rate analysis from simulation and experiment were compared. The simulation results meet the data specification with the experimental results, both in trends and values.

\section{Table 1}

\begin{tabular}{ll}
\multicolumn{2}{l}{ Engine and Injection specification $[12,14]$} \\
\hline Engine specification \\
\hline Bore $(\mathrm{m})$ & 0.085 \\
Stroke $(\mathrm{m})$ & 0.087 \\
Connecting rod length $(\mathrm{m})$ & 0.13 \\
Bowl diameter $(\mathrm{m})$ & 0.0463 \\
Bowl depth $(\mathrm{m})$ & 0.016 \\
Compression ratio & 18 \\
Engine speed (RPM) & $1600,2000,2400$ \\
\hline Injection specification & \\
\hline Type of injection & Direct injection \\
Number of nozzles & 4 \\
Injection pressure (MPa) & 19.613 \\
Injection duration ( $\left.{ }^{\circ} \mathrm{CA}\right)$ & 16 \\
Injection timing ( ${ }^{\circ} \mathrm{CA}$ BTDC) & 18 \\
Injection profile & Single-injection \\
\hline
\end{tabular}

\subsection{Grid Independence Test}

Besides validation against the experiment and simulation from previous study [12], grid independence test were conducted to choose and fit the most suitable base grid size to forecast the combustion event and emission in this work. Figure 2 shows the validation of simulation to the experimental study with the convergence analysis from in-cylinder pressure resulted from different base grid sizes. The grid independence test is conducted with 3 different grid sizes of $3 \mathrm{~mm}, 4 \mathrm{~mm}$, and $5 \mathrm{~mm}$. The best base grid size is then used throughout all the simulations with the constant scale of fixed embedding and AMR. These features will allow the software to improve the orthogonal meshing for better analysis accuracy. Other than convergence analysis from the simulation results, simulation duration and file size capacity were also considered and compared.

Table 2 shows the results of the grid independence test by comparing the error percentage between simulation and experiment at TDC point and peak pressure point. The result shows that there is about a 3\% difference for the in-cylinder peak pressure between the $3 \mathrm{~mm}$ and $4 \mathrm{~mm}$ base case. The file size capacity and simulation duration were also compared. Time taken to carry out the simulation shows a significant difference between all grid sizes carried out especially on the $3 \mathrm{~mm}$ grid size. Due to the small difference in in-cylinder peak pressure between $3 \mathrm{~mm}$ and $4 \mathrm{~mm}$, base grid of $4 \mathrm{~mm}$ has been selected as the optimum grid size in this work. Moreover, a comparison between simulation results and experiments with another study [12] also suggested that $4 \mathrm{~mm}$ is the optimum grid size. 


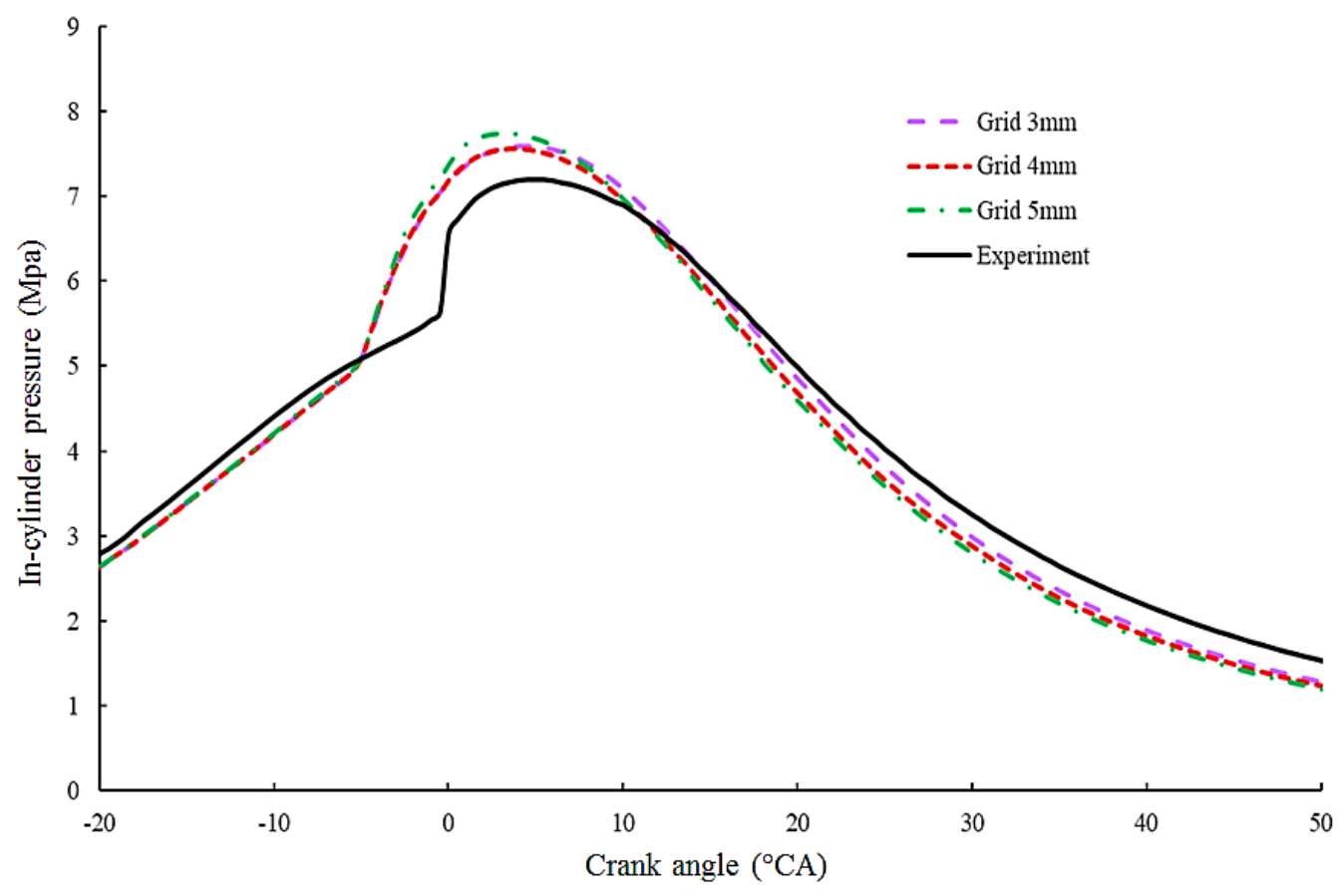

Fig. 2. Grid independence test from CFD simulation and the experiment validations

Table 2

Grid independence test results

\begin{tabular}{lllll}
\hline \multirow{2}{*}{ Grid size } & \multicolumn{2}{l}{ Percentage difference (\%) } & File size (GB) & Simulation time (min) \\
\cline { 2 - 4 } & At TDC & Peak Pressure & & \\
\hline $3 \mathrm{~mm}$ with AMR & 8.424 & 5.1209 & 14.0 & 1557 \\
$4 \mathrm{~mm}$ with AMR & 8.1896 & 4.0239 & 7.76 & 996 \\
$4 \mathrm{~mm}$ without AMR & 14.3179 & 7.8170 & 6.14 & 439 \\
$5 \mathrm{~mm}$ with AMR & 10.8481 & 6.1449 & 4.87 & 664 \\
\hline
\end{tabular}

\subsection{Combustion Characteristics and Emission Analysis}

Ethanol as the low reactive fuel (LRF), was injected into the intake manifold, as soon as the air entering the combustion chamber when the intake valve open (IVO) as shown in Figure 3. Meanwhile, diesel fuel as the high reactive fuel (HRF), was directly injected into the combustion chamber at -18 ${ }^{\circ} \mathrm{CA}$ BTDC for $16^{\circ} \mathrm{CA}$ duration with a single injection profile as explained in Table 1 . Ethanol was used as the low reactive fuel and chosen as the best fuel compared to other alcohols because ethanol has the lowest density and viscosity which provides good injection shape and leads to good atomization. Table 3 shows the thermo-physical properties of diesel as high reactivity fuel and ethanol as low reactivity fuel.

The injection of ethanol in the intake manifold was set in the simulation initialization set up by considering the ethanol occupied the air in the intake manifold by 22 vol\%. The temperature and pressure of intake air were set at ambient conditions. The SOI of high reactive fuel and engine speed will give a significant effect on the performance of the RCCl engine. In this study, the effects of these parameters on the $\mathrm{RCCl}$ engine combustion and emissions were investigated. The fuel injection parameters listed in Table 1 were used throughout the simulation. To achieve this goal, six different primary cases of engine parameters have been chosen namely as cases $A, B, C, D, E$, and $F$ as shown in Table 4. 


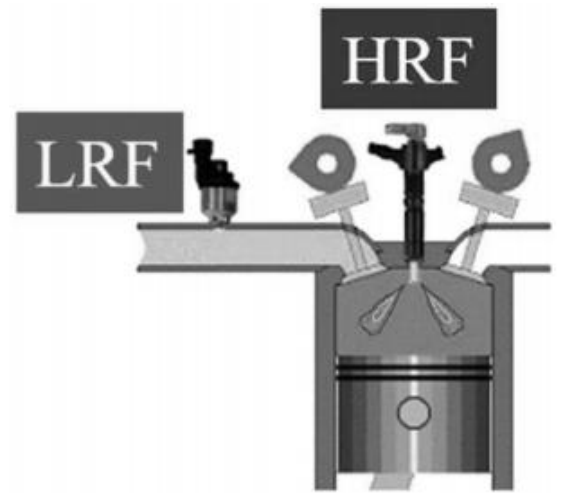

Fig. 3. $\mathrm{RCCl}$ engine schematic diagram [15]

Table 3

Thermo-physical properties of diesel and ethanol [16]

\begin{tabular}{lll}
\hline Thermo-physical properties & Diesel & Ethanol \\
\hline Density @ 293K $\left(\mathrm{kg} / \mathrm{m}^{3}\right)$ & 837 & 788 \\
Cetane number & 50 & $5-8$ \\
Kinematic viscosity @ 313K $\left(\mathrm{mm}^{2} / \mathrm{s}\right)$ & 2.6 & 1.2 \\
Surface tension $(\mathrm{N} / \mathrm{m})$ & 0.023 & 0.015 \\
Low calorific value $(\mathrm{MJ} / \mathrm{kg})$ & 43 & 26.8 \\
Heat capacity $\left(\mathrm{J} / \mathrm{kg} .{ }^{\circ} \mathrm{C}\right)$ & 1850 & 2100 \\
Boiling point $\left({ }^{\circ} \mathrm{C}\right)$ & $180-360$ & 78 \\
Oxygen contents $(\%)$ & 0 & 34.8 \\
Molecular weight $(\mathrm{kg} / \mathrm{mol})$ & 170 & 46 \\
\hline
\end{tabular}

Table 4

Different primary cases with different parameters

\begin{tabular}{lll}
\hline Cases & Speed & Injection timing \\
\hline Case A & 1600 RPM & $-18^{\circ}$ CA BTDC \\
Case B & 2000 RPM & $-18^{\circ}$ CA BTDC \\
Case C & 2400 RPM & $-18^{\circ}$ CA BTDC \\
Case D & 1600 RPM & $-15^{\circ}$ CA BTDC \\
Case E & 1600 RPM & $-18^{\circ}$ CA BTDC \\
Case F & 1600 RPM & $-20^{\circ}$ CA BTDC \\
\hline
\end{tabular}

\section{Results and Discussion}

\subsection{Effect of Engine Speed on Combustion Characteristics}

The engine speed of case $A, B$, and $C$ were increased while the diesel fuel injection timing was kept constant. The result in Figure 4 shows that the combustion duration has been prolonged, and the peak pressure was decreased and the fuel ignitability is dramatically decreased. Increasing the engine speed shortened the time available for the mixture to get homogenous. Hence, the number of regions with relatively high reactivity is decreased and delay the ignition. Therefore, in this case, the peak pressure point occurs near the TDC. The rate of mixing between diesel fuel and intake air and ethanol affects the ignition delay at high-temperature heat-release (HTHR). Mixing the diesel fuel with intake air and ethanol should be in balance. Low fuel-air intake mixing rate results in a higher diesel-rich region [17], which tends to increase the $\mathrm{NO}_{x}$ and soot emissions. Meanwhile, a high mixing rate resulted in a low equivalence ratio reaction, hence, the reactivity for the combustion to occur is reduced. 


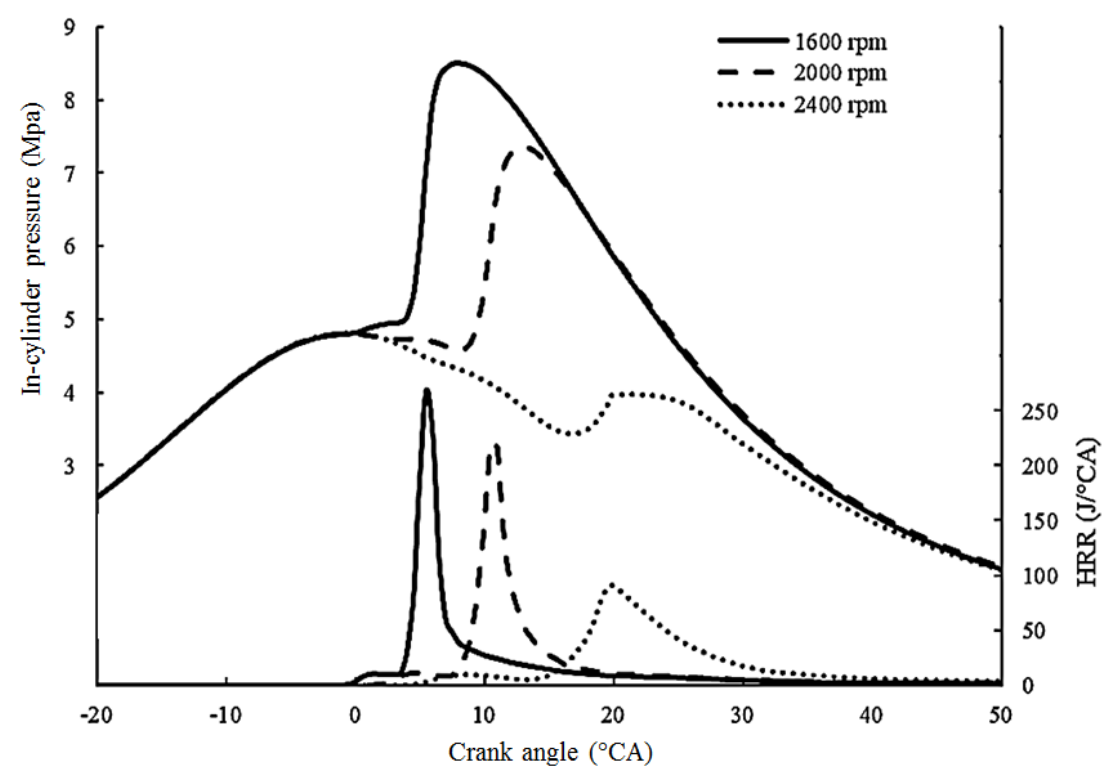

Fig. 4. In-cylinder pressure and heat release rate (HRR) against crank angle of diesel-ethanol combustion at different engine speed

\subsection{Effect of Engine Speed on Emissions}

Case $\mathrm{A}, \mathrm{B}$, and $\mathrm{C}$ results in lower $\mathrm{NO}_{\mathrm{x}}$ and soot when the engine speed increased as shown in Figure 5.
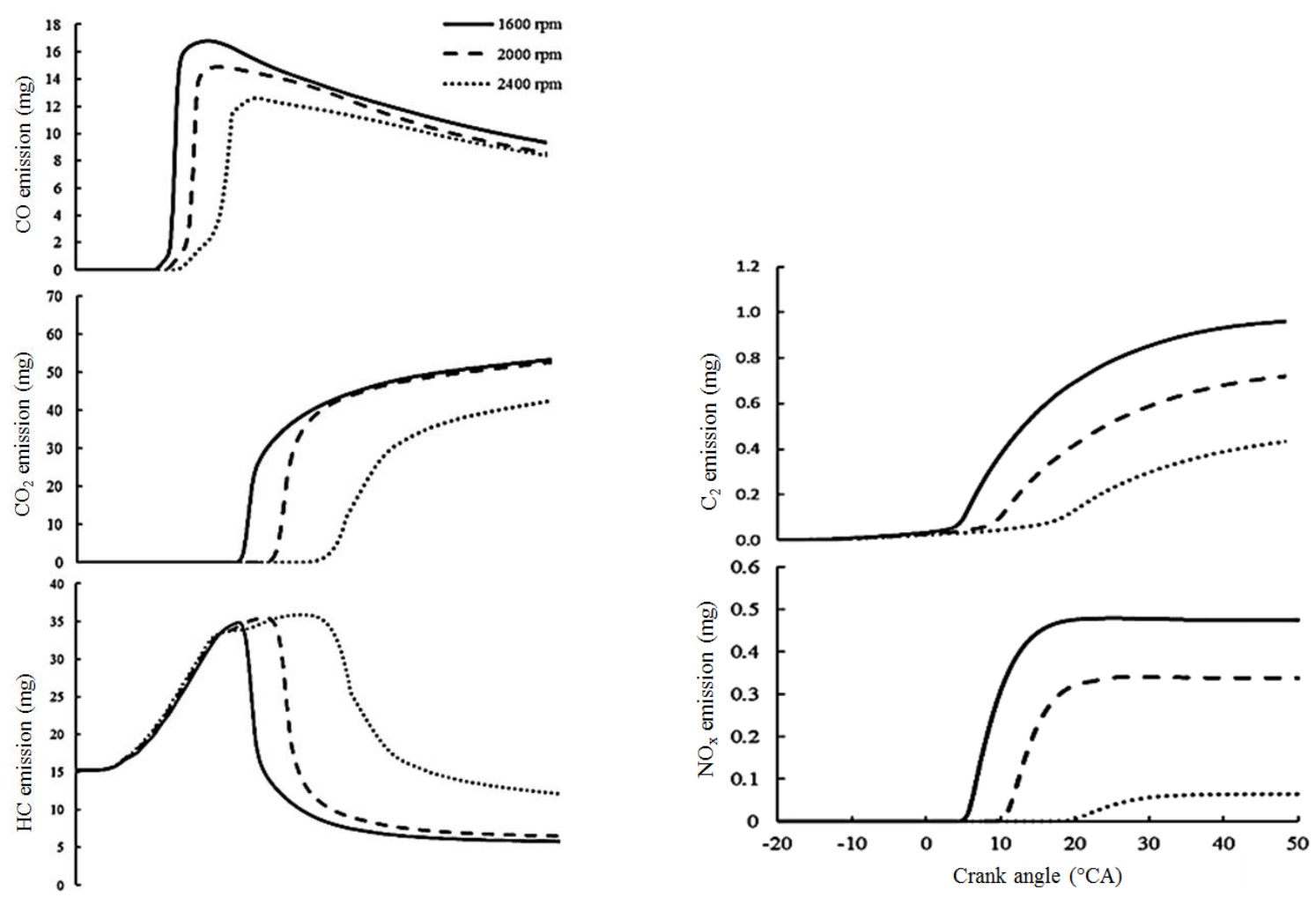

Fig. 5. Emissions of diesel-ethanol combustion operated in different engine speed

Meanwhile, the emission of $\mathrm{CO}, \mathrm{CO}_{2}, \mathrm{C}_{2}$, and $\mathrm{NO}_{\mathrm{x}}$ is decreased with the increase of engine speed. High engine speed operation limits the air intake and leads to incomplete combustion due to 
insufficient air. The thermal efficiency and indicated specific fuel consumption (ISFC) trend with the combustion phase shows that high engine speed resulting in higher engine efficiency due to lower heat transfer to the cylinder walls. The higher engine speed has higher pumping and leads to heat loss to the exhaust. However, these thermal losses were less than the efficiency gains and not significantly influenced the engine efficiency. Similar to the findings from Splitter et al., [18], higher thermal efficiencies from gasoline-diesel reactions with the single-fuel strategy, had high combustion efficiency, although the work done during the compression stroke is found negative.

\subsection{Effect of Injection Timing on Combustion Characteristics}

Diesel injection strategies influenced the combustion behavior in the engine. The injection timing of diesel is varied to study the effect of injection timing on the combustion characteristics and emissions of combustion. In cases $D, E$, and $F$, where the injection timing was varied with constant engine speed.

Figure 6 shows the in-cylinder pressure and HRR of diesel-ethanol combustion running at a constant engine speed of 1600 RPM with different diesel fuel injection timing. The graph shows that the peak pressure in these cases is slightly higher than cases $A, B$, and $C$. This indicates that any retard injection decision in the $\mathrm{RCCl}$ engine should be made wisely, since cases $\mathrm{D}, \mathrm{E}$, and $\mathrm{F}$ deal with a high average temperature and extended ringing intensity. In terms of peak heat release rate in $H T H R$, it can be concluded that SOI timing at $-20^{\circ} \mathrm{CA}$ ATDC has the highest HRR followed by $-18^{\circ} \mathrm{CA}$ ATDC, and then $-15^{\circ} \mathrm{CA}$ ATDC. The heat release rate at HTHR is affected by the reactivity gradient in the combustion chamber so that, rapid combustion can occur with the premixed of air and ethanol. The level of reactivity should be balanced, so that the distribution of diesel fuel can spread over the entire region in the combustion chamber. Hence, the energy to burn more ethanol fuels is enough. This explains the situation of the higher heat release in HTHR at the SOI timing of $-20^{\circ} \mathrm{CA}$ ATDC.

Figure 6 and Figure 7 show the increased in-cylinder pressure and temperature in the combustion chamber with the different injection timing. From the graph, the SOI at $-20^{\circ} \mathrm{CA}$ ATDC produces the highest peak pressure and temperature followed by $-18^{\circ} \mathrm{CA}$ ATDC, and the lowest is at $-15^{\circ} \mathrm{CA}$ ATDC. The combustion at $-20^{\circ} \mathrm{CA}$ ATDC produces the highest pressure and increases the temperature, because of the combustion of the diesel fuel which is not mixed well with the intake air-ethanol in the combustion chamber.

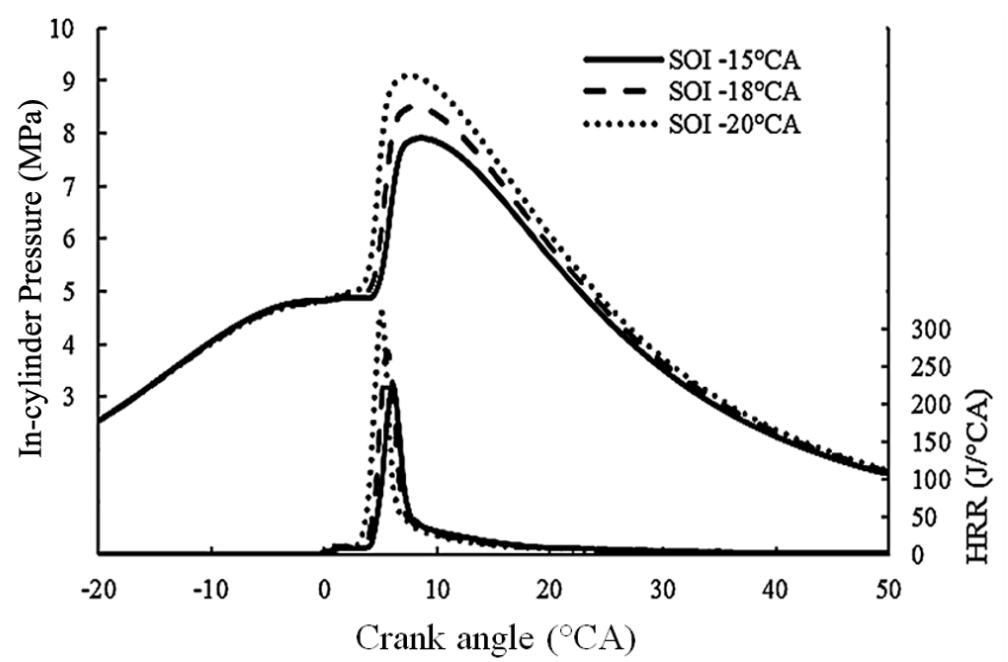

Fig. 6. In-cylinder pressure and HRR of diesel-ethanol combustion in $\mathrm{RCCl}$ engine with different injection timing strategies 


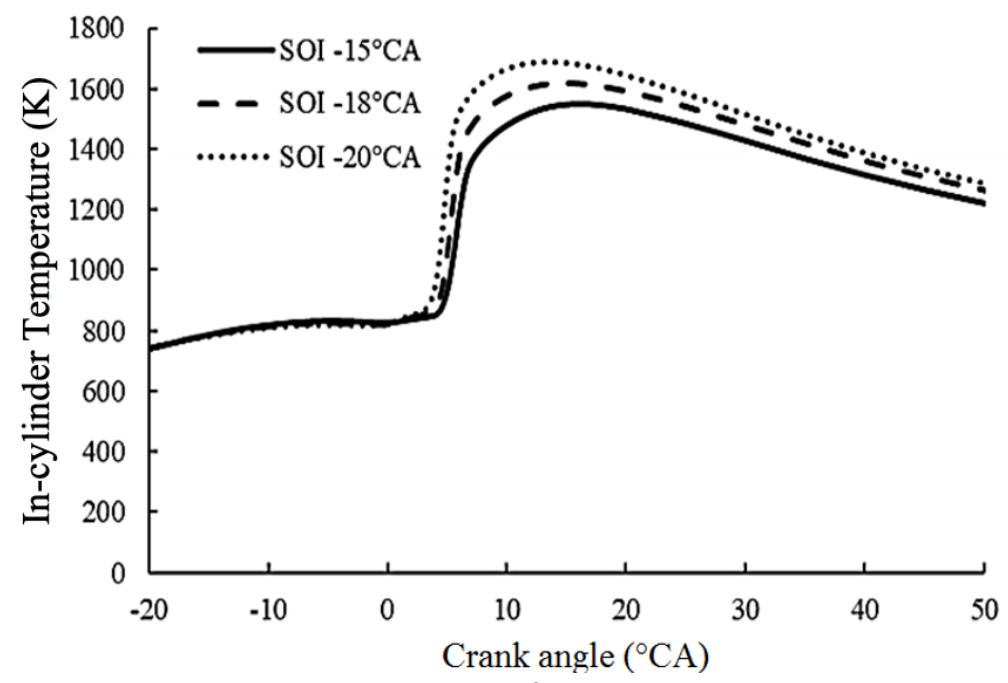

Fig. 7. In-cylinder temperature of diesel-ethanol combustion in $\mathrm{RCCl}$ engine operated with different injection timing strategies

\subsection{Effect of Injection Timing on Emissions}

Figure 8 shows the result of emissions such as $\mathrm{HC}, \mathrm{CO}, \mathrm{NO}_{\mathrm{x}}$, and soot. In Figure 8 , the $\mathrm{SOI}$ of $15^{\circ} \mathrm{CA}$ ATDC produces the lowest emission of $\mathrm{NO}_{\mathrm{x}}$, and $-20^{\circ} \mathrm{CA}$ ATDC produces the highest $\mathrm{NO}_{\mathrm{x}}$ compared to other SOI.
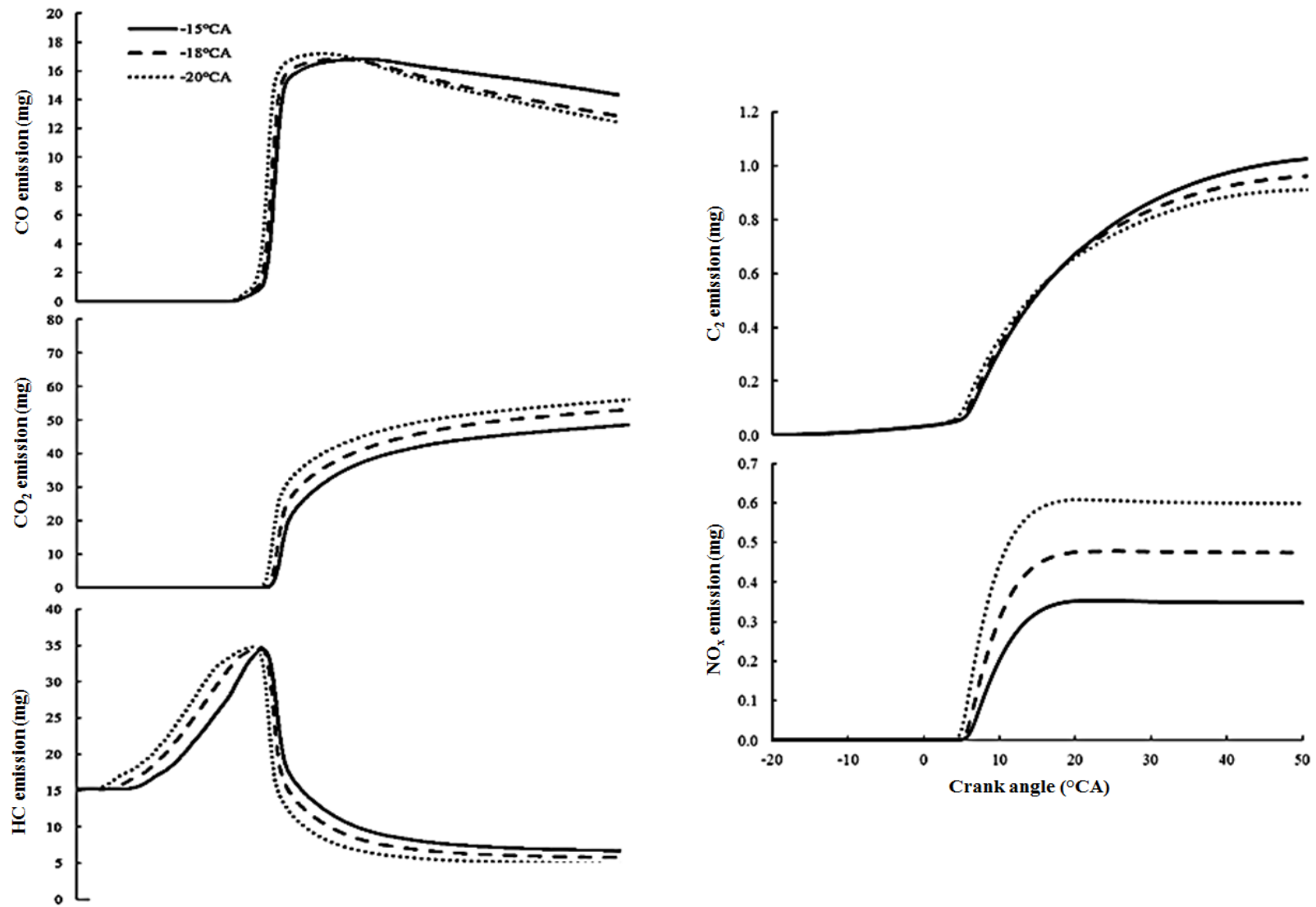

Fig. 8. Emissions of diesel-ethanol combustion in RCCl engine operated with different injection timing strategies 
The graph shows that the SOI of $-20^{\circ} \mathrm{CA}$ ATDC produces the lowest soot compared to other SOI. The reason is that the unmixed diesel fuel reacts and leads to complete combustion, especially at LTHR. During this phase, more oxygen is available and allows more complete combustion to happen. $\mathrm{SOI}$ at $-15^{\circ} \mathrm{CA}$ ATDC granted higher soot due to the low reactivity gradient in the combustion chamber to encourage the combustion.

Figure 8 also shows the emissions of $\mathrm{HC}$ and $\mathrm{CO}$. There can be seen on these two graphs that $\mathrm{HC}$ and $\mathrm{CO}$ emissions are the lowest when the diesel injection is retarded at $-20^{\circ} \mathrm{CA}$ ATDC followed by $18^{\circ} \mathrm{CA}$ ATDC and $-15^{\circ} \mathrm{CA}$ ATDC. This shows that SOI $-20^{\circ} \mathrm{CA}$ ATDC allows more complete fuel combustion occurred. The factor affecting the low release of the $\mathrm{HC}$ and $\mathrm{CO}$ emission is due to the high in-cylinder peak temperature which helped to burn more fuels.

\section{Conclusions}

In the study, major important parameters on the start of injection and combustion duration of an $\mathrm{RCCl}$ engine were studied in detail and extensively for all different possible circumstances. This paper provides data on diesel combustion and the emission effects with the presence of ethanol as low reactive fuel in the $\mathrm{RCCl}$ engine concept for further experiment consideration. Diesel injection timings were optimized for maximum efficiency while varying the engine speed. Exhaust emissions and performance of the most efficient cases were discussed. The primary findings can be summarised as follows

i. The engine speed range from 1600 to $2400 \mathrm{rpm}$ shows that the duration of the fuel-air mixture to get homogenous is shorter, so the number of regions with relatively high reactivity increases.

ii. Advance injection provides more time for diesel fuel to mix with the intake of air and ethanol, hence, forming a more balanced equivalence ratio and reactivity gradient. Better combustion progress occurs throughout the combustion chamber.

iii. Diesel and ethanol reduced the emissions of NOx and soot for a better environmental future and better engine performance. At the higher speed, diesel and ethanol fuels in the RCCI engine reduced the $\mathrm{NO}_{\mathrm{x}}$ and soot emissions

Delaying the SOI reduced the $\mathrm{HC}$ and $\mathrm{CO}$ emissions, but with a slight increment of NOx and soot emissions. Due to the delay of SOI, the reactivity gradient in the combustion chamber increases and allows more fuel to be combust.

\section{Acknowledgement}

The authors would like to thank Universiti Kebangsaan Malaysia for supporting this research with grant GUP-2018-099.

\section{References}

[1] Jishnu Sreenath and Anand Oai. "Biodiesel: a review on next generation fuels." Journal of Advanced Research in Fluid Mechanics and Thermal Sciences 43, no. 1 (2018): 58-66.

[2] Yilmaz, Nadir, Francisco M. Vigil, A. Burl Donaldson, and Tariq Darabseh. "Investigation of Cl engine emissions in biodiesel-ethanol-diesel blends as a function of ethanol concentration." Fuel 115 (2014): 790-793.

https://doi.org/10.1016/i.fuel.2013.08.012

[3] Aydin, Hüseyin, and Cumali Ilkılıc. "Effect of ethanol blending with biodiesel on engine performance and exhaust emissions in a Cl engine." Applied Thermal Engineering 30, no. 10 (2010): 1199-1204. https://doi.org/10.1016/i.applthermaleng.2010.01.037

[4] Jagadeesh Prashanth, Alappat Joseph Antony and Sher Afghan Khan. "Experimental Investigation on the 
Performance of Single Spark Ignition and Twin Spark Ignition Engine Fuelled with Ethanol-Gasoline Blends." Journal of Advanced Research in Fluid Mechanics and Thermal Sciences 65, no. 1 (2020): 25-41.

[5] Prashant, G. K., D. B. Lata, and P. C. Joshi. "Investigations on the effect of ethanol blend on the combustion parameters of dual fuel diesel engine." Applied Thermal Engineering 96 (2016): 623-631.

https://doi.org/10.1016/i.applthermaleng.2015.11.051

[6] Huang, Jincheng, Yaodong Wang, Shuangding Li, Anthony P. Roskilly, Hongdong Yu, and Huifen Li. "Experimental investigation on the performance and emissions of a diesel engine fuelled with ethanol-diesel blends." Applied Thermal Engineering 29, no. 11-12 (2009): 2484-2490.

https://doi.org/10.1016/i.applthermaleng.2008.12.016

[7] Benajes, Jesús, Santiago Molina, Antonio Garcia, and Javier Monsalve-Serrano. "Effects of direct injection timing and blending ratio on $\mathrm{RCCl}$ combustion with different low reactivity fuels." Energy Conversion and Management 99 (2015): 193-209. https://doi.org/10.1016/i.enconman.2015.04.046

[8] Hanson, Reed, Sage Kokjohn, Derek Splitter, and Rolf Reitz. "Fuel effects on reactivity controlled compression ignition (RCCl) combustion at low load." SAE International Journal of Engines 4, no. 1 (2011): 394-411. https://doi.org/10.4271/2011-01-0361

[9] Ma, Shuaiying, Zunqing Zheng, Haifeng Liu, Quanchang Zhang, and Mingfa Yao. "Experimental investigation of the effects of diesel injection strategy on gasoline/diesel dual-fuel combustion." Applied Energy 109 (2013): $202-212$. https://doi.org/10.1016/i.apenergy.2013.04.012

[10] Qian, Yong, Linqi Ouyang, Xiaole Wang, Lifeng Zhu, and Xingcai Lu. "Experimental studies on combustion and emissions of RCCI fueled with n-heptane/alcohols fuels." Fuel 162 (2015): 239-250. https://doi.org/10.1016/i.fuel.2015.09.022

[11] Nazemi, M., and M. Shahbakhti. "Modeling and analysis of fuel injection parameters for combustion and performance of an RCCl engine." Applied Energy 165 (2016): 135-150.

https://doi.org/10.1016/j.apenergy.2015.11.093

[12] Ibrahim, Fadzli, Wan Mohd Faizal Wan Mahmood, Shahrir Abdullah, and Mohd Radzi Abu Mansor. Comparison of Simple and Detailed Soot Models in the Study of Soot Formation in a Compression Ignition Diesel Engine. No. 201701-1006. SAE Technical Paper, 2017.

https://doi.org/10.4271/2017-01-1006

[13] Richards, K. J., P. K. Senecal, and E. Pomraning. "Converge (version 2.2. 0) manual, convergent science." Inc., Madison, WI (2014).

[14] Norhidayah Mat Taib, Mohd Radzi Abu Mansor, Wan Mohd Faizal Wan Mahmood, and Nik Rosli Abdullah. "Simulation Study of Combustion Characteristics of DieselEthanol-Palm Oil Methyl Ester Blends in Diesel Engine." Journal of Advanced Research in Fluid Mechanics and Thermal Sciences 44, no. 1 (2018): 149-156.

[15] Eichmeier, Johannes Ulrich, Rolf Reitz, and Christopher Rutland. "A zero-dimensional phenomenological model for $\mathrm{RCCl}$ combustion using reaction kinetics." SAE International Journal of Engines 7, no. 1 (2014): 106-119. https://doi.org/10.4271/2014-01-1074

[16] Lu, Jiang, and Andrew A. Pouring. Development of a New Concept Piston for Alcohol Fuel Use in a Cl Engine. No. 961078. SAE Technical Paper, 1996. https://doi.org/10.4271/961078

[17] Curran, Scott J., Reed M. Hanson, and Robert M. Wagner. "Reactivity controlled compression ignition combustion on a multi-cylinder light-duty diesel engine." International Journal of Engine Research 13, no. 3 (2012): 216-225. https://doi.org/10.1177/1468087412442324

[18] Splitter, Derek, Rolf Reitz, and Reed Hanson. "High efficiency, low emissions RCCl combustion by use of a fuel additive." SAE International Journal of Fuels and Lubricants 3, no. 2 (2010): 742-756.

https://doi.org/10.4271/2010-01-2167 